\title{
Cellular mechanisms of phase maintenance in the pyloric motif
}

\author{
Gabrielle E O'Brien ${ }^{1}$, William H Barnett ${ }^{2}$, Gennady S Cymbalyuk 2* $^{*}$ \\ From Twenty Second Annual Computational Neuroscience Meeting: CNS*2013 \\ Paris, France. 13-18 July 2013
}

Many biological motor patterns such as leech and lamprey swimming, ventilation in crabs and food particle filtration in crustaceans are maintained in a range of frequencies. This phenomenon is well-studied in the crustacean pyloric network, a central pattern generator (CPG) which produces a distinct bursting pattern with three-to-fivefold changes in period [1-4]. The flexibility of the network output requires neurons to adjust their temporal characteristics, such as burst duration, interburst interval and time to firing from synaptic input, in order to maintain their phase in the network pattern as the period changes. Recently, it has been shown that the coordinated neuromodulation of currents in pyloric neurons is a cellular mechanism sufficient to support phase maintenance $[3,4]$.

In the model neuron reported here, coordinated variation of the voltages of half-activation for the potassium $\left(\theta_{\mathrm{K} 2}\right)$ and hyperpolarization-activated $\left(\theta_{\mathrm{h}}\right)$ currents provides a family of dynamical mechanisms for fine control of burst duration, interburst interval and latency to spiking. The mechanisms are determined by a global codimension-2 bifurcation, the Cornerstone bifurcation with bifurcation parameters $\theta_{\mathrm{K} 2}$ and $\theta_{\mathrm{h} .}$. In Mechanism 1, the burst duration of a bursting neuron grows arbitrarily large as $\theta_{\mathrm{K} 2}$ approaches a blue sky catastrophe, and the interburst interval grows arbitrarily large as $\theta_{\mathrm{h}}$ approaches a SNIC bifurcation. We found level sets of duty cycle using an analytical approximation imposed by the Cornerstone bifurcation. These level sets describe coordination of the parameters that could be realized through neuromodulation. In Mechanism 2, a silent neuron exhibits a single burst in response to synaptic inhibitory input; the duration of the burst is determined by $\theta_{\mathrm{K} 2}$. In Mechanism 3, a spiking neuron exhibits a

\footnotetext{
* Correspondence: gcymbalyuk@gsu.edu

${ }^{2}$ Neuroscience Institute, Georgia State University, Atlanta, GA, 30303, USA Full list of author information is available at the end of the article
}

pause before firing in response to synaptic inhibitory input; the duration of the pause is determined by $\theta_{\mathrm{h}}$.

When applied to neurons connected in a pyloric motif, the family of mechanisms allows the neurons to maintain phase with one another as period grows up to fivefold. We consider three models: all three neurons are endogenously bursting (Mechanism 1), a pacemaker neuron is bursting and the follower neurons are silent (Mechanisms 1 and 2, Figure 1), and a pacemaker neuron is bursting and the follower neurons are spiking (Mechanisms 1 and 3). In each model, the pacemaker neuron maintains duty cycle with increasing period and the follower neuron's parameters are coordinated to match. These mechanisms are generic, cellular in essence, and not sensitive to synaptic parameters.

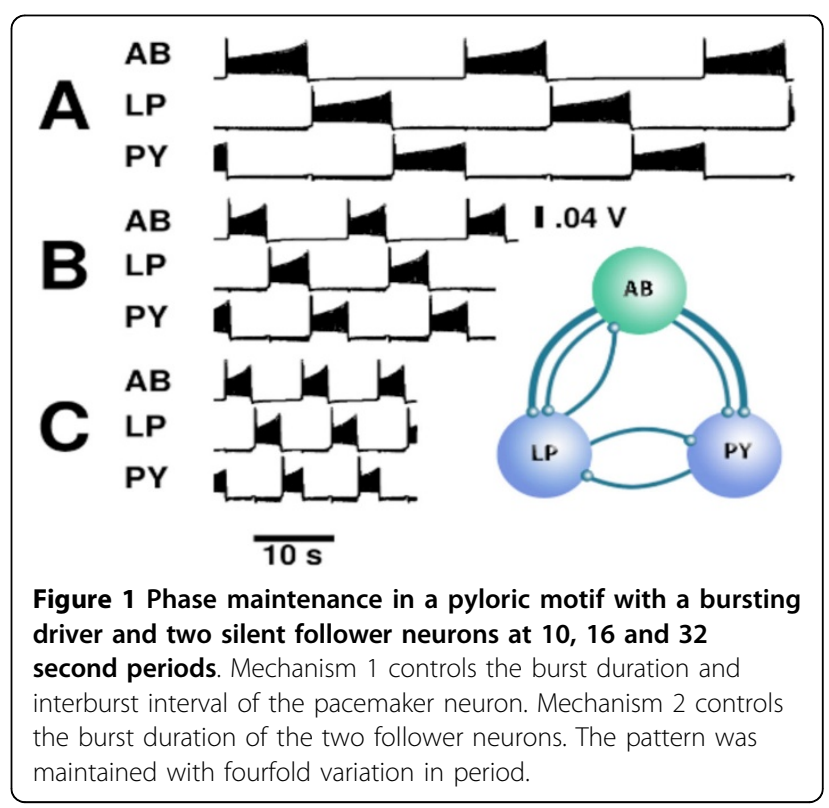

C Biomed Central

( 2013 O'Brien et al; licensee BioMed Central Ltd. This is an Open Access article distributed under the terms of the Creative Commons Attribution License (http://creativecommons.org/licenses/by/2.0), which permits unrestricted use, distribution, and reproduction in any medium, provided the original work is properly cited. 


\section{Author details}

'Mathematics, Agnes Scott College, Decatur, GA, 30030, USA. ${ }^{2}$ Neuroscience

Institute, Georgia State University, Atlanta, GA, 30303, USA.

Published: 8 July 2013

\section{References}

1. Mouser C, Nadim F, Bose A: Maintaining phase of the crustacean triphasic pyloric rhythm. J Math Biol 2008, 57(2):161-181

2. Hooper SL, Buchman E, Weaver AL, Thuma JB, Hobbs KH: Slow conductances could underlie intrinsic phase-maintaining properties of isolated lobster (Panulirus interruptus) pyloric neurons. J Neurosci 2009, 29(6):1834-1845

3. Soofi W, Archila S, Prinz AA: Co-variation of ionic conductances supports phase maintenance in stomatogastric neurons. J Comput Neurosci 2012, 33(1):77-95.

4. Marder E, Bucher D: Understanding circuit dynamics using the stomatogastric nervous system of lobsters and crabs. Annu Rev Physiol 2007, 9:291-316.

doi:10.1186/1471-2202-14-S1-P76

Cite this article as: O'Brien et al.: Cellular mechanisms of phase maintenance in the pyloric motif. BMC Neuroscience 2013 14(Suppl 1):P76.

\section{Submit your next manuscript to BioMed Central} and take full advantage of:

- Convenient online submission

- Thorough peer review

- No space constraints or color figure charges

- Immediate publication on acceptance

- Inclusion in PubMed, CAS, Scopus and Google Scholar

- Research which is freely available for redistribution

Submit your manuscript at www.biomedcentral.com/submit 